\title{
INTERSECCIONALIDADES E A EDUCAÇÃO ESPECIAL NA PERSPECTIVA DA EDUCAÇÃO INCLUSIVA
}

Marcos Cezar de Freitas ${ }^{\mathrm{I}}$

Larissa Xavier dos Santos ${ }^{\text {II }}$

I Universidade Federal de São Paulo (Unifesp), Guarulhos (SP), Brasil; marcos.cezar@unifesp.br

II Educinep: Educação Inclusiva na Escola Pública, Universidade Federal de São Paulo (Unifesp), Guarulhos (SP), Brasil; larissa.xs92@gmail.comr

\section{Resumo}

O objetivo deste artigo é evidenciar que, nas pesquisas sobre a escolarização de crianças com deficiência ou cronicamente enfermas, as interseccionalidades com questões de gênero, raça, classe social e etnia são fundamentais. A análise foi conduzida com base nesse pressuposto, considerado aqui estruturante da educação inclusiva. Para levar a efeito uma narrativa que validasse esse pressuposto, metodologicamente foram utilizadas informações obtidas em longos esforços etnográficos com adultos que acompanham crianças registradas como público-alvo da educação especial em suas respectivas escolas. A conclusão a que chegamos foi a de que, sem criticar os enquadramentos de gênero, raça e classe que presenciamos, as corporalidades em questão não teriam sido analisadas em perspectiva inclusiva.

EDUCAÇÃO INCLUSIVA • EDUCAÇÃO ESPECIAL • ETNOGRAFIA • RELAÇÕES RACIAIS

\section{INTERSECTIONALITIES AND SPECIAL EDUCATION ON THE PERSPECTIVE OF THE INCLUSIVE EDUCATION}

\section{Abstract}

The purpose of this article is to show that in research on the schooling of children with disabilities or chronically ill, intersectionality with issues of gender, race, social class and ethnicity are fundamental. The analysis was conducted based on this assumption, considered here as structuring of inclusive education. In order to carry out a narrative that validates this assumption, methodologically, information obtained in long ethnographic efforts with adults who accompany children registered as a target audience for special education in their respective schools was used. The conclusion we reached was that without criticizing the frameworks of gender, race and class that we witness the corporealities in question would not have been analyzed in an inclusive perspective.

INCLUSIVE EDUCATION • SPECIAL EDUCATION • ETHNOGRAPHY • RACE RELATIONS 


\section{INTERSECCIONALIDADES Y LA EDUCACIÓN ESPECIAL EN LA PERSPECTIVA DE LA EDUCACIÓN INCLUSIVA \\ Resumen}

El objetivo de este artículo es mostrar que en la investigación sobre la escolarización de niños con discapacidad o enfermedades crónicas las interseccionalidades con cuestiones de género, raza, clase social y etnia son fundamentales. El análisis se realizó sobre la base de esta suposición, considerado aquí estructurante de la educación inclusiva. Para llevar a cabo una narrativa que validara esa suposición, metodológicamente fueron utilizadas informaciones obtenidas en largos esfuerzos etnográficos con adultos que acompañan a los niños registrados como público objetivo de la educación especial en sus respectivas escuelas. La conclusión a la que llegamos fue que sin criticar los marcos de género, raza y clase que presenciamos las corporalidades en cuestión no habrian sido analizadas en una perspectiva inclusiva.

EDUCACIÓN INCLUSIVA • EDUCACIÓN ESPECIAL・ETNOGRAFÍA•RELACIONES RACIALES

\section{INTERSECTIONNALITÉS ET ÉDUCATION SPÉCIALE DANS LA PERSPECTIVE DE L'ÉDUCATION INCLUSIVE}

\section{Résumé}

L'objectif de cet article est de montrer que les intersectionnalités des questions de genre, de race, de classe sociale et d'ethnicité sont fondamentales dans les recherches sur la scolarisation des enfants handicapés ou souffrant de maladies chroniques. L'analyse s'appuie sur cette hypothèse, considérée comme structurante de l'éducation inclusive. Pour mettre en œuvre un récit qui puisse valider cette hypothèse, la démarche méthodologique a consisté à collecter des informations obtenues au cours de longs entretiens ethnographiques auprès d'adultes s'occupant d'enfants, public cible de l'éducation spéciale, inscrits dans leurs écoles respectives. Nous en avons conclu que sans une critique des normes de genre, de race et de classe qui prévalent, il n'aurait pas été possible d'analyser les corporalités en question dans une perspective inclusive.

ÉDUCATION INCLUSIVE • ÉDUCATION SPÉCIALE • ETHNOGRAPHIE • RELATIONS RACIALES 
FINAL DE SETEMBRO DE 2020, PROFESSORES E PESQUISADORES QUE TRABALHAM com a educação, mas com repertórios analíticos da educação inclusiva, foram surpreendidos com a publicação do Decreto n. 10.502/2020 que homologou a "nova" Política Nacional de Educação Especial formulada pelo Ministério da Educação (MEC).

Seu conteúdo causou perplexidade e indignação, a começar pelo desrespeito à Lei Brasileira de Inclusão n. 13.146 (2015), culminando com a descaracterização completa da Política Nacional de Educação Especial na Perspectiva da Educação Inclusiva (PNEEPEI) de 2008 (Ministério da Educação, 2008). Direitos assegurados na Constituição da República Federativa do Brasil de 1988 (1988) e que repercutiram na Lei de Diretrizes e Bases da Educação Nacional n. 9.394 (1996) também foram desconsiderados. Convenções internacionais das quais o Brasil é signatário sequer foram mencionadas. Um expressivo retrocesso se anunciava com pompa e circunstância.

Do ponto de vista dos que pesquisam esse universo e têm experiência acompanhando dificuldades que se mostram diretamente no chão da escola e das instituições, é importante também acrescentar objeções que se apresentaram nessa preocupação com o esvaziamento de perspectivas críticas, que há pelo menos quatro décadas adensam análises a respeito. Queremos apresentar resultados de pesquisas que a nosso ver demonstram que a PNEEPEI (Ministério da Educação, 2008), ora sob ataque, suscita a aproximação necessária em relação às perspectivas interseccionais de análise. Nessa aproximação se consolida a acepção de inclusão que desde 2008 tentamos, como sociedade, acrescentar à educação especial, ampliando seu universo de pesquisa, de base empírica, análise e reflexão.

A PNEEPEI (Ministério da Educação, 2008), no modo como a entendemos, não é apenas uma referência normativa, mas é também um horizonte crítico para a pesquisa educacional que pode, em relação às pessoas com deficiência, apropriar-se de repertórios analíticos mais densos.

Educação inclusiva toma por ponto de partida que deficiência se intersecciona com as dimensões de gênero, raça, etnia e classe social e, como em um caleidoscópio, mostra-se com diversificada combinação de formas (Ministério da Educação, 2008).

As personagens da educação inclusiva, cuja presença na escola comum ampliou-se significativamente nos últimos 30 anos, resultado das garantias obtidas com sucessivos marcos legais, nacionais e internacionais, ainda são predominantemente abordadas com base em descrições de supostas insuficiências orgânicas, fisiológicas, anatômicas, sensoriais e intelectuais. Ou seja, mesmo com a perspectiva da educação inclusiva, essas pessoas ainda são predominantemente consideradas por meio de inventários de (in)capacidades e descritas com base no detalhamento do que corporalmente lhes falta.

Nesse sentido, o que ocorrerá se abdicarmos dos esforços cumulativos com os quais tentamos compreender essa realidade, imbuídos que estamos da convicção que cumpre a nós evitar reducionismos biológicos?

Em 2008, a Política Nacional de Educação Especial, que estava em vigência desde 1994, foi objeto de uma retificação em seu escopo e em seus propósitos. Com a publicação da PNEEPEI (Ministério da Educação, 2008) ampliávamos nossa percepção a respeito dos direitos educacionais da pessoa crônica ou gravemente enferma e, principalmente, da pessoa com deficiência.

Reconhecíamos que os corpos dessas pessoas são inseparáveis de suas dimensões socioculturais, em cujo sentido encontramos camadas sobrepostas de complexidade em que se materializam também questões de gênero, raça, etnia e classe social. 
Esses pressupostos da educação inclusiva nem sempre têm sido considerados (Freitas, 2013). Continua necessário afirmar que não existem corporeidades cujas características mais complexas não se interseccionem com outras dimensões da existência. Nessas dimensões percebemos a construção social de sofrimentos que só de forma aparente resultam exclusivamente das "insuficiências do corpo" (Shakespeare, 2010).

Berckmoes e Reis (2017), percebendo isso, consideraram que as dificuldades vividas com o próprio corpo deveriam ser analisadas com base naquilo que denominaram "idiomas culturais do sofrimento social”. Sugeriram uma lupa analítica para que, com lentes de aumento, visualizemos os próprios protagonistas lidando com suas especificidades, "sentindo na pele" (Berckmoes \& Reis, 2017, p. 10) as intersecções entre aspectos estruturantes de suas existências.

Apreender situações em que determinados atores "sentem na pele" os efeitos das assimetrias a que estão sujeitos exige contínuos esforços etnográficos para levar a efeito abordagens que considerem a pesquisa com esses critérios de observação e análise. Por isso, perspectivas interseccionais acrescentam uma dimensão de pesquisa com a qual as chamadas dificuldades da inclusão se deixam ver, se desvelam.

Para dar concretude e esse argumento, o presente artigo aborda a presença de crianças negras cronicamente enfermas matriculadas em escolas públicas, crianças essas que mantêm rotinas ambulatoriais diárias em um local público de saúde em São Paulo, capital. Essas situações são contrastadas com a experiência de crianças negras com deficiência, matriculadas em uma escola pública de local periférico de uma grande cidade da região metropolitana de São Paulo.

São duas pesquisas, com o mesmo fundamento teórico-metodológico, propositalmente conduzidas em bases territoriais distintas, realizadas no bojo de um amplo projeto institucional que aborda a educação inclusiva em escolas públicas. Pela unidade teórica e continuidade metodológica que têm, essas pesquisas, ao mesmo tempo que revelam questões singulares em cada uma, também são situações variáveis e comparáveis de uma mesma indagação investigativa.

Nossa intenção é a de "passar a lupa" sobre o cotidiano de crianças que têm sido analisadas como se as suas experiências de escolarização resultassem de particularidades exclusivamente descritas em seus laudos e prontuários. Ou seja, queremos compartilhar uma dimensão da pesquisa voltada ao universo da educação inclusiva que, efetivamente, depende do reconhecimento de intersecções para desvelar a complexidade de seu objeto, que é o corpo como construção social.

Reconhecemos intersecções para defender um ponto de vista, o de que a educação inclusiva, mais do que uma perspectiva, tornou-se irrenunciável para uma educação especial que não se deixe capturar por expectativas segregadoras.

\section{O ollhar no microscópio}

O que será exposto resulta de extenso processo de investigação, com dinâmicas que envolveram pesquisa participante e estratégias próprias da perspectiva antropológica de aproximação, permanência e registro de acontecimentos.

As pesquisas que permitiram anotar informações em cadernos de campo, observar intensamente e entrevistar sujeitos adultos ${ }^{1}$ responsáveis pelas crianças destacadas abrangeram mais de quatro anos de esforço etnográfico.

1 As crianças descritas nas pesquisas que são mencionadas neste artigo são legal e eticamente protegidas com base nas vulnerabilidades que caracterizam suas situações. Foram observadas com autorização de seus responsáveis e a abordagem direta restringiu-se aos interlocutores adultos nos cenários de pesquisa. Os processos aprovados no Comitê de Ética da Unifesp são CEP 296.901/2013, CEP 30.714.814.5.0000.5505/2015 e CEP 2.936.887/2018. 
No mundo próprio de significação dos contextos estudados foi possível obter acesso aos modos de cada um(a) se ver na trama, acolhendo pontos de vista nativos que se configuravam na experiência vivida. Cada personagem demonstrava modos peculiares de lidar com o próprio corpo, corpo esse permanentemente indicado como problemático. Por isso, as observações feitas com grande proximidade também permitiram analisar o impacto de ser permanentemente apontado(a), descrito(a) e classificado(a). Com base no que a proximidade e a constância no convívio proporcionavam foi possível perceber enquadramentos de gênero, raça e classe social sem os quais as vulnerabilidades corporais que justificavam os modos de permanecer e usar as instituições ficariam restritas à descrição de déficits orgânicos. Esses enquadramentos plasmaram o sentido de limitação corporal e de deficiência que se construíam em cada situação.

Quatro crianças têm destaque na análise que será apresentada. Duas, uma menina com 11 e um menino com 10 anos, protagonizam os exemplos que serão pormenorizados e que foram recolhidos em "interações face a face" (Goffman, 2012) presenciadas em um ambulatório de alergias graves, cujo conteúdo estigmatizante era também reiterado na experiência escolar de cada uma, conforme depoimentos recolhidos.

As cenas registradas nesse universo de observação serão comparadas com situações observadas em outro cenário, uma escola pública. Nessa escola pública, outras duas crianças, uma menina de 5 e um menino de 11 anos, experimentaram aspectos da construção de suas corporalidades que também se tornaram inseparáveis dos enquadramentos de gênero, raça e classe social que permeavam as noções de corpo elaboradas ali, dentro de circunstâncias muito específicas.

As quatro crianças, que receberão nomes fictícios, são negras, mas isso não diz respeito a qualquer "essência" (Brah, 2006). Corporalidade é um conceito com o qual se reconhece que "o corpo se faz", não que está feito (Scott, 1995). Esse “fazer-se” (Davis, A., 2010) ou esse "tornar-se” (Hall, 2005) é a matéria analítica deste artigo.

Se são crianças negras cronicamente enfermas ou com deficiência, essas características são, na perspectiva que adotamos, expressões de como "tornar-se" é também experiência histórica concreta que permite entender os dispositivos debilitadores e deficientizadores de nossa sociedade quando focamos o tecido social, não as debilidades do corpo.

As experiências serão comparadas e os enquadramentos de gênero, raça e classe social serão demonstrados com exemplos, de modo a favorecer uma compreensão crítica sobre como personagens concretas (Goffman, 2011) experimentam de vários modos a perspectiva de "excluídos no interior" elaborada por Bourdieu (2005).

No ambulatório e na escola em que permanecemos como pesquisadores, as pessoas foram comunicadas sobre nossa presença e autorizaram que observássemos e tomássemos nota do que víamos. O primeiro critério de registro era observar, ouvir e anotar.

O critério para entrevistar alguém era o de pedir detalhamento sobre algum comentário em cujo conteúdo fosse possível perceber dados significativos sobre a experiência de cada criança. Mas a principal estratégia não era a da entrevista e sim a da escuta proporcionada pela proximidade (autorizada), que permitia testemunhar longas horas de espera. Isso praticamente organizava rodas de conversas. Quando a entrevista ocorria, o ponto de partida era a situação imediatamente vivida e, portanto, não decorria de um roteiro preestabelecido. Com o Termo de Consentimento Livre e Esclarecido obtivemos também autorização para gravar as falas.

No ambulatório recolhemos opiniões e comentários (que serão apresentados como pequenos excertos neste artigo, sempre entre aspas e, quando necessário, com a identificação de quem falou na sequência, entre parênteses, garantindo anonimato) de mães, enfermeiras, médicos(as) e servidoras administrativas. Na escola, obtivemos manifestações de professoras(es), gestoras(es), coordenação pedagógica, estagiárias, auxiliares da vida escolar (AVE) e merendeiras. Com exceção de uma criança, conseguimos dialogar repetidas vezes com as mães. 
A constância, a permanência e o convívio quase diário geraram situações nas quais a familiaridade com nossa presença (Corsaro, 2005) suscitou pedidos de ajuda para a organização de filas, distribuição de informações e solicitações que amiúde criavam um sentimento de pertença que iludia a todas(os) nós, como se estivéssemos dentro da mesma trama, o que pelo menos favorecia um contato com a linguagem cotidiana de modo a flagrar, como sugere Geertz (2000), conteúdos que se diferenciam em pequeníssimos gestos.

\section{A percepção de enquadramentos}

Nas "experiências de enquadramento" (Butler, 2015; Crenshaw, 2002; Goffman, 2016) presentes no cotidiano ambulatorial ou escolar de cada criança analisada, gênero, raça e classe social são camadas sobrepostas e, por isso mesmo, não podem ser consideradas aspectos que simplesmente se justapõem. Enquanto categorias configuradoras recíprocas da experiência social, uma vez que despontam interseccionadas ou consubstanciadas (Hirata, 2014), fazem um todo que é maior do que a soma das partes. Por isso, as personagens deste artigo "se fizeram" na experiência e com a experiência concreta de serem meninas(os) negras(os) pobres cronicamente enfermas(os) ou com deficiência (Brah, 2006, 2019).

Mais precisamente, afirmamos que não eram, mas se tornavam meninas(os) negras(os) pobres cronicamente enfermas(os) ou com deficiência na medida em que suas identidades se conformavam naquilo que lhes faltava diante de outros (Hall, 2005; Brah, 2019), e também no modo como se apropriaram de uma descrição de si que partia sempre da constatação dessas "faltas" (Goffman, 2000, 2013).

Especificamente no que diz respeito à presença do corpo adoecido ou com deficiência, somente é possível uma abertura à perspectiva interseccional se as marcas desses corpos não forem tomadas como "desvantagem natural". Nosso ponto de partida a esse respeito é o mesmo de Tremain (2017), que se distancia das classificações acadêmicas que se recusam a incorporar esses corpos em qualquer análise interseccional ou mesmo simplesmente integrada, como se adoecimentos e deficiências fossem acontecimentos à parte (Tremain, 2017). Essas recusas fazem com que tais presenças sejam sempre abordadas como se fossem um dado da natureza a desafiar um dado da cultura.

O adoecimento crônico e a deficiência são experiências que se vivem no plural, ao lado de, diante de, em relação a (Bluebond-Langner, 2000). "Viver entre", "ter a mediação de", "depender de", "fazer com", "fazer para" são situações que conectam pessoas e os corpos são reelaborados permanentemente no âmbito das interdependências que assim são construídas. Como se verá adiante, no âmbito das interdependências aqui descritas, as questões de gênero foram decisivas para a configuração de papéis e para a elaboração de expectativas de (in)sucesso (Goffman, 2014).

Tal como reforçam os disability studies (Diniz, 2010), a própria designação "pessoa com deficiência" indica um esforço para demonstrar que é o corpo na sociedade e com a sociedade que possibilita compreender uma identidade em elaboração, sem separar da pessoa, sempre em processo, as questões que permeiam a sua existência (McRuer \& Johnson, 2014). Por isso, não foi casual a aproximação ocorrida nos últimos 20 anos do século XX entre os disability studies e os estudos feministas, que acrescentaram importantes reflexões sobre o tema gênero no universo das pessoas cronicamente enfermas ou com deficiências. Segundo Haraway (2004), as teorias feministas de gênero se tornaram imprescindíveis para esse universo porque focaram a análise do corpo com a densidade de estudos culturais que negaram os binarismos básicos de natureza/cultura, natureza/história, natural/humano, recursos/produtos.

A percepção das questões raciais é profundamente interseccionada com questões de gênero e de classe social (Brah, 2006; Crenshaw, 2002; Davis, A., 2010). Isso remete nosso esforço analítico a diversos movimentos políticos que se fizeram levantando uma bandeira de identidade negra $\mathrm{e}$ trabalhadora, com exemplos internacionais expressivos, como o contexto britânico investigado por Avtar Brah, ou o contexto estadunidense abordado por Angela Davis. 
Barton (2017), por exemplo, descreve a particularidade de pessoas negras com deficiência no contexto da Grã-Bretanha, onde os processos de estigmatização de imigrantes os colocavam no papel de "invasores" e "agregados". Mas entre aqueles “indesejáveis", as pessoas negras com deficiência tinham ainda menos espaço no mercado de trabalho, o que limitava inclusive a partilha de representações da dignidade construídas com "ideologias do trabalho redentor", ficando à margem até das narrativas mistificadoras e opressivas.

Se raça é uma categoria cultural/situacional que não se restringe a um fenótipo, a singularidade de ser negra(o) e deficiente ou doente crônica(o) acrescenta ao processo expressiva invisibilidade, ou aquilo que Goffman $(2000,2012)$ denomina "presença ignorada”.

A subjetividade é constituída na relação do indivíduo com o espaço social, e é assim que a particularidade do sujeito passa por um processo de significação que permite experienciar esse transcurso como aquele(a) identificável (Brah, 2006).

Apresentam-se também os desafios postos pelas expectativas de capacidade e incapacidade associadas às pessoas. A categoria "capacitismo" (Mello, 2016) tornou-se estratégica para definir preconceitos específicos contra pessoas com deficiência ou cronicamente enfermas, sendo um equivalente a termos como sexismo e racismo (Mozzi \& Nuernber, 2017). O capacitismo diz respeito aos corpos capazes sempre pensados com seus antípodas, os corpos incapazes. Temos capacitismo quando uma percepção de "falta" identifica um todo corpóreo como incapaz.

Epistemologicamente, a abordagem interseccional permite compreender a identidade que se consubstancia com gênero, raça, classe social, plasmando um corpo concreto, histórico, assim configurado. Configuração que Hirata (2014, p. 66) denominou "interseccionalidade de geometria variável”, o que é bastante adequado para perceber deficiências para além dos marcadores biomédicos que as acompanham.

Gomes e Lopes (2017) argumentam, com base em Garland-Thomson (2002), que a cultura impregna as peculiaridades do corpo e consequentemente a constituição de seus significados. Em muitas situações já se sabe, de antemão, quem "não é" "não pode", "não consegue". Esse "saber antes" corresponde àquilo que Goffman (2000) considera como espectro de expectativas do qual a pessoa não escapa, uma cicatriz social, "um estigma”.

Os exemplos que serão explorados demonstrarão como Tom Shakespeare (1999) tem razão ao explicitar que feminilidade, adoecimento e deficiência reforçam-se de modo simultâneo, enquanto adoecimento, deficiência e masculinidades socialmente se contradizem.

Com a presença recorrente de cisões não naturais entre feminino e masculino no âmbito das deficiências e do adoecimento crônico, um denso universo de análise se descortina e nos desafia com exemplos que demonstram que esses autores estão corretos. Vamos, então, à exemplificação anunciada para que possamos, ao final, analisar o conteúdo das situações expostas.

\section{Experiências de pele (ou "aqui todo mundo é preto")}

Abordaremos inicialmente as experiências de Mara, menina negra com 11 anos de idade, e de Gino, menino negro com 10 anos de idade. Ambos os nomes são fictícios e ambas as crianças faziam parte do grupo que pelo menos em três manhãs, entre segunda e sexta-feira, comparecia ao Ambulatório de Alergia e Imunologia de um grande hospital público da cidade de São Paulo.

Compunham o grupo que era acompanhado terapeuticamente para controle de dermatites atópicas graves, combinadas com quadros severos de asma. As rotinas ambulatoriais se conectavam às rotinas escolares, pois as crianças atendidas se deslocavam para as respectivas escolas no final das manhãs, indicando um cotidiano intensamente institucionalizado, entremeado por longos processos de deslocamento na cidade. 
Chegavam muito cedo, depois de pelo menos duas horas em transporte público, provenientes das longínquas bases territoriais da periferia da Zona Sul de São Paulo. Permaneciam até aproximadamente $10 \mathrm{~h} 30$ e voltavam aos próprios bairros, para suas escolas. Estudavam em locais diferentes, em escolas públicas, e tinham permissão previamente assegurada para entrarem com atraso, o que frequentemente acontecia em decorrência das demandas ambulatoriais.

Um ambulatório com as características desse que oportunizou quatro anos de pesquisa etnográfica tem espaços que são pequenos prolongamentos da vida escolar. A faixa etária atendida e a constância com a qual as crianças comparecem fazem com que muitas lições de casa sejam feitas ali, em meio ao brincar que se desenvolve entre aquelas(es) que têm experiências coletivas de espera, longa espera, até o aguardado chamado das(os) doutoras(es).

Há troca de informações entre as crianças que fazem os deveres de casa, intercâmbio de material e também resolução de questões a muitas mãos. Despontam entre as pessoas adultas comparações sobre como as crianças são tratadas em suas respectivas escolas e como "os corpos que têm" (enfermeira) repercutem no desempenho escolar. São pessoas adultas que seguidamente afirmam que "conhecem as crianças que têm”. E, nesse sentido, uma questão de gênero chamou a atenção. Em todo o período de observação as crianças foram acompanhadas predominantemente por mães e avós. Uma única vez registrou-se a presença de um pai e foram muitas as ocasiões em que mulheres se queixaram da exaustão pela sobrecarga. Expressavam com palavras próprias inconformidade com a naturalização do papel reservado às mulheres nessa trama diária, ao mesmo tempo que algumas afirmavam que "homens não saberiam o que fazer".

As mães de Mara e Gino reivindicavam a condição de "mais experientes", e isso repercutia no modo como demonstravam conhecer o local e as minúcias de seu funcionamento. Identificavam o som do ônibus que trazia servidoras administrativas (uma delas com a chave para abrir a porta interna) e, principalmente, o som dos carros da equipe médica, composta por dois médicos e duas residentes. Com a experiência de reconhecer quem se aproximava, organizavam aquilo que Goffman (2014) definiu como "porte" e associou à "deferência".

Para esse autor, em microespaços é possível flagrar cenas em que cada um(a) organiza o próprio corpo, o porte, considerando a presença de outro(s). Nesse cenário de pesquisa, as mulheres invariavelmente levantavam-se quando os jalecos brancos adentravam, aproximavam os corpos das crianças laçando-as com as mãos e olhavam para aquelas(es) que entravam, mas, em nenhuma ocasião, retribuíam com olhares ou saudações. Passavam olhando para o alto e para frente.

Esse levantar-se demonstra a deferência, uma vez que esse gesto não se dava em relação às demais profissionais. Estas faziam aquilo que Goffman (2014) denomina "deixar pegar o olhar", ou seja, desde o primeiro momento proporcionavam interações face a face com mães e, principalmente, com as crianças, demonstrando ora afeto, ora autoridade geracional pedindo silêncio, por exemplo.

Foi no diálogo entre as mães de Mara e Gino com enfermeiras que despontou a percepção de que ali se configurava um território "não branco" (mãe de Gino). Pois salientaram que usavam aquele serviço médico tão distante de casa porque eram, antes de tudo, pessoas pobres e tinham dúvida se a distância contida naquele modo de "nem virar o pescoço para dar bom dia" (mãe de Mara) era um distanciamento com demarcação racial ("a gente é tudo preto") ou de classe social ("mas a gente não estaria aqui se não fosse pobre"), ou ambos, porque inúmeras vezes despontava uma forma jocosa de referir-se ao grupo de mães e crianças nos diálogos de balcão ("na sala de espera todo mundo é preto", mãe de Gino).

Das enfermeiras recebiam indicações que demonstravam uma percepção mais ampla das assimetrias sociais ("usem isso aqui como quem tem direito, não como quem recebe de favor"). Mas delas recebiam também recomendações para que atenuassem o desconforto em relação ao comportamento dos médicos ("são assim mesmo, não liguem"). 
Quanto à recomendação para "não ligar", outra perspectiva de gênero rapidamente se mostrou, na medida em que muitas indicavam perceber que "eram tratadas como mulher” (mãe de outra criança). $\mathrm{Na}$ realização da pesquisa, foi possível registrar inúmeros diálogos que demonstravam indignação, pois consideravam ser "grande desconsideração" (mãe de Gino) os médicos não se dirigirem às mães diretamente. Quando um doutor solicitava "fale para sua mãe que essa pomada tem que passar todo dia", mesmo com a mãe ao lado da criança na consulta, ou quando não disfarçava a desconfiança perguntando "sua mãe falou que você não quer tomar o remédio, é verdade?" percebíamos grande indignação, expressa com eloquência facial.

Na soma, foi possível entender, tal como sugere Florence Weber (2010) em sua etnografia com mulheres, que as percepções de lugar e de serviço se associavam, nas falas e comentários, às "características de locais não pagos" (várias mães) e, estes, ao infortúnio das camadas populares. Essa é uma percepção que em certo sentido Bourdieu (2005) flagrou em A miséria do mundo quando pessoas em situações com grandes assimetrias sociais desenvolvem a opinião de que recebem algo que se parece com o que pensam que são.

\section{Menina ou menino: variações sobre o mesmo tema}

Nada permitiu concluir que o atendimento médico fosse desprovido de qualidade e zelo, o que, por outro lado, confirmava que os pontos de tensão estavam nas configurações interpessoais, com seus respectivos "modos de ser" (Goffman, 2014) e "modos de estar" (Goffman, 2011).

Sempre extenuadas, aquelas mulheres se queixavam que ninguém considerava a distância que percorriam, o tempo que esperavam e, principalmente, que "viviam para aquelas crianças" (todas as mães), já que muitos companheiros "não aguentaram tanta complicação" (mãe de Gino) e foram embora.

Isso fez com que aquelas mães lançassem mão de um modo singular de abordar as crianças (especialmente Mara e Gino) com a mediação de palavras que aludiam à cor da pele e à performance esperada de um menino e de uma menina.

As crianças eram advertidas frequentemente para que não "mexessem no que é dos outros", mas as advertências (especialmente para a mãe de Gino) serviam para reforçar o entendimento de que "todo mundo já desconfia se a pessoa não é branca, e se ainda dá motivo mexendo no que é dos outros, fica parecendo que tá pra roubar”.

Mas o temor recorrente àquilo que "fica parecendo ser" em algumas circunstâncias tornava-se um fardo pesado especialmente para Gino.

O quadro clínico de sua pele era preocupante e, além disso, a presença da asma como agravante complementar fazia com que voltasse ao ambulatório mais vezes que os demais. Era também aquele que mais vezes fora internado, em momentos de crise. Apesar disso, Gino recebia contínuas sinalizações para que lidasse mais apropriadamente com suas fragilidades. Mais apropriadamente significava "como homem" (sua mãe).

Em muitas ocasiões escutou, não somente de sua mãe, mas também de outras mulheres, incluindo pessoas do staff, que "na verdade o problema sério dele era a asma, porque menino não tem problema de pele” (mãe de Gino, com a corroboração da enfermeira). Menino "pode mostrar o corpo", "pode ter cicatriz" que "tudo fica bem, porque não precisa ter vaidade" (ambas).

A asma, limitadora de movimentos e agitações, era considerada uma inibidora da masculinidade, uma vez que exigia do menino um "parar quieto" (mãe de Mara) que só "as meninas aguentam" (mãe de Mara e de Gino).

Por isso, as dermatites eram experiências vividas, tal como percebeu Shakespeare (1999) no fluxo de reforço da fragilidade enquanto feminina, como disse a mãe de Mara: "a menina, que tem vaidade, ela sim sofre com a doença de pele”. Já a asma era projetada no fluxo da potência enquanto 
masculina, como disse a mãe de Gino, "pense um menino que não pode correr, coitado, como se fosse menina que é mais parada”. Eram situações permeadas de complexidade porque todas as crianças ali presentes tinham, simultaneamente, asma e dermatites atópicas graves.

A resistência que Gino vez ou outra apresentava para despir-se para a verificação médica despertava impaciência em quase todas as personagens adultas. Mas nos dias em que essa impaciência se intensificava, era no enquadramento como menino que Gino era chamado às falas com ameaças: "se quer fazer que nem menina vai ser tratado como menina" (mãe ameaçando vestir-lhe uma calcinha).

Mara resistia a permanecer parada aguardando e corria, brincava, ainda que isso resultasse algumas vezes em ofegâncias muito preocupantes. Mara "parecia menino" (sua mãe) de tanto que se mexia. Mas parecia menino somente na inquietude de seus modos e gestos, porque o feminino em suas reações era exaltado por todas as mães no momento de mostrar a pele, pois "virava bicho, se tivesse que tirar a roupa”.

\section{As conexões com a escola}

Algumas das falas de adultas(os) no cenário de acompanhamento ambulatorial tinham pontos de encontro ou convergências que se mostravam acima das assimetrias sociais ali claramente visíveis.

Possivelmente $\mathrm{o}$ aspecto mais convergente mostrava-se quando entrava em cena a argumentação que elencava as prioridades na vida de cada criança em tratamento. Convergiam para o mesmo modo de falar todos(as) que insistiam que "a principal tarefa de cada criança era reconhecer suas limitações corporais".

Com base nesse pressuposto, que era assertivamente repetido e lembrado quando as crianças se esqueciam das limitações, tudo mais em termos de expectativas para o devir jovem e adulto despontava de modo condicionado (“ou entende o que pode e o que não pode, ou só vai sofrer nessa vida”, mãe de Gino).

Representações de consciência e conscientização marcavam claramente a distância entre classes sociais nos diálogos, como na advertência do médico que exortou uma mãe afirmando "a senhora pode não ter estudo, mas é capaz de lembrar pra ela o que não adianta querer, porque não pode".

Desnecessária a demarcação curricular ("pode não ter estudo") se o objetivo fosse dialogar sobre vulnerabilidades previsíveis quando aspectos da pele e da asma são desconsiderados. Mas o primeiro objetivo não era esse. A advertência adentrava o espaço de interlocução com marcações de lugar social que preveniam responsabilidades futuras. Repetidas vezes o médico advertia "depois não adianta reclamar".

No contexto que se configurava, a fala de ciência não era contestada, ou melhor, não era contestável, não somente em razão da profunda assimetria de poder que naquele microespaço se materializa, mas também porque a fala de ciência era reapropriada por mães como estratégia para dialogar com a escola.

Não vimos rispidez no tratamento que fosse suficiente para inibir cooperações certificadas. Ou seja, mesmo em momentos mais tensos era sempre possível registrar pedidos de atestados, laudos e declarações "para que a escola acreditasse" (mãe de Mara).

Esses instrumentos de perícia médica nunca foram negados e proporcionavam atenuações nas falas que eram comemoradas ("assim eles acreditam na senhora") e apropriadas como se pudessem conectar a escola às expectativas de impossibilidade que acompanhavam cada uma daquelas crianças.

Se a transmissão de percepções sobre a vulnerabilidade proporcionava diálogos intergeracionais (Berckmoes \& Reis, 2017) que enquadravam o feminino e o masculino "adequado" a cada corpo (Butler, 2015; Goffman, 2016), era também em modo intergeracional que algumas estratégias de resistência se expressavam, algumas com base na ideia de "fazer valer o que se tem" (mãe de Gino). 
Em relação ao universo escolar daquelas crianças, a alusão ao "fazer valer" revestia-se de uma ambiguidade verificável nas situações em que a experiência do sofrimento em comum articulava uma espécie de idioma local (Rockwell, 2014; Santillan, 2017), quase um repertório cultural com o qual as vulnerabilidades eram ensinadas com recursos para perceber o próprio lugar social, para lembrar-se da cor da pele, para não esquecer prerrogativas do masculino/feminino e, como síntese, para organizar o modo de estar enquanto pessoa cronicamente enferma.

A ambiguidade a que nos referimos diz respeito à repercussão dessas experiências no universo escolar dessas crianças, especialmente de Mara e Gino. A vida escolar estava sempre presente, mas, em meio às tarefas que ali eventualmente se realizavam, um argumento ganhava centralidade pela recorrência.

As escolas, especificamente professoras(es), eram elogiadas (por mães, servidoras(es) e médicos(as)) quando despontavam exemplos com os quais se demonstrava que "foi percebido que não adianta pedir muito" (mães de Mara e Gino).

Facilmente se apresentava a unanimidade com a qual aquelas crianças eram tomadas como incompatíveis com a dinâmica escolar. Essa percepção ali generalizada promovia uma expressiva descaracterização da noção de educação inclusiva, uma vez que inúmeras vezes as escolas eram elogiadas como verdadeiramente inclusivas quando reconheciam que a criança tinha "o direito de não ser cobrada" (mães de Mara e Gino).

Essa era considerada a "principal vantagem" de receber do ambulatório a documentação pericial formalizada nos diagnósticos e laudos, pois com essas "cédulas de identidade" (médico) a escola teria facilidade em reconhecer que a criança "não consegue como as demais" (mãe de Gino).

Produzia-se uma situação na qual a educação inclusiva era elogiada por não ser inclusiva, uma vez que a expectativa de escolarização era, a priori, considerada inadequada, passando a ser a permanência na escola associada, paradoxalmente, à possibilidade de não permanecer, não ficar, não entrar quando necessário e, fundamentalmente, não receber conteúdos “incompatíveis" com a condição de cronicamente enferma(o).

Realizava-se aquilo que Martinez e Rey (2017, p. 110) expressaram com temor quando analisaram o entendimento geral de educação inclusiva e advertiram ser crucial compreender que a criança não recebia, com a inclusão, o direito à não educação, ao contrário disso.

E todas as singularidades corporais no contexto se interseccionavam com uma perspectiva de classe que, ao termo, dirigia-se à escola pública como se ela fosse subalterna e incompleta e, por isso mesmo, chamada a "reconhecer seu lugar de assistência" (médico).

Essa interpelação à escola pública, desrespeitando-a, se mostrava em falas pretensamente consoladoras como "nessa hora é até bom estar na escola pública que não tem exigência, porque na particular acho que não aguentaria” (médico, residente, mãe de Mara), e também em falas que indicavam, com referência ao organismo das crianças, o que nessas instituições "não encontrariam jamais", como "um ambiente sem pó", "produtos que não causam alergia", "enfermaria” (médicos e residentes).

Conseguimos entrevistar a professora de Mara visitando sua escola. Obtivemos informações importantes que demonstravam preocupação com a perda de conteúdos causada pelas faltas e pelas saídas motivadas por crises respiratórias. Mas registramos também uma expressão de afeto que corroborava a expectativa de "não presença" (Goffman, 2012) ou que materializava o "excluído no interior" (Bourdieu, 2005).

Como poderia uma expressão de afeto suscitar a aplicação de categorias tão impregnadas de sofrimento social? Isso se deu quando a professora afirmou que "o momento mais feliz" acontecia quando Mara pegava no sono na sua carteira e o "melhor presente para ela era deixar descansar". 


\section{Identidades reais e virtuais (ou "aqui ninguém é preto")}

Vamos ampliar o movimento de análise deslocando o foco para duas crianças matriculadas em escola pública da periferia de uma grande cidade da região metropolitana de São Paulo.

Os procedimentos de pesquisa no âmbito da escola foram os mesmos referidos no tempo de permanência no ambulatório. A intenção de proporcionar às personagens nossa postura de escuta e observação garantiu, do mesmo modo que os cadernos de campo, que se registrassem aspectos microscópicos, fundamentais para que as intersecções entre problemas sociais e deficiências se mostrem efetivamente.

Entram em cena Rosa e Renan com 5 e 11 anos de idade, respectivamente, e o cenário é uma escola pública que atende crianças desde a educação infantil até o ano final do fundamental I. O bairro é periférico e passou por mudanças demográficas na última década com instalações de grandes comércios, conservando, porém, déficits urbanos consideráveis, entre os mais graves os relacionados a saneamento básico. Trata-se de um local em que as pessoas mencionam que com exceção de alguns "todo mundo é pobre".

A gestão da escola mostrou-se acolhedora e tornou o ambiente escolar repleto de gravuras, recortes e cartazes que sinalizavam "orgulho pelo trabalho social da escola" (coordenadora pedagógica). Isso se desdobrava em projetos temáticos e, dentre esses, o tema da participação política congraçando famílias e professores era recorrente. Participação política na maioria das vezes era traduzida pelo esforço para obter melhorias no bairro, tecnologia assistiva para a escola, segurança e transporte.

A escola possui um pátio logo na entrada, ao lado do qual está o refeitório e em volta estão as salas de aulas. Há uma rampa para acessar outras salas de aula em um segundo piso e ao fundo há um parque com uma quadra, seis balanços, uma casinha, dois escorregadores e um canto de areia da cor verde, onde as crianças brincam. Há também um palco com um pequeno acervo de livros para uso espontâneo e um computador preparado para o manejo, também espontâneo, das crianças.

A escola é reconhecida pelo trabalho com crianças com deficiência. $\mathrm{Na}$ fila de espera para voltar para casa usando o veículo da prefeitura foi possível observar, para além de Rosa e Renan, outras crianças, com destaque para uma com grande redução de mobilidade provocada por paralisia cerebral e outra com nenhuma comunicação verbal.

Há quantidade significativa de crianças negras ainda que, surpreendentemente, na sala de Rosa, ela fosse a única. Na turma de Renan estão presentes mais três meninos negros. Entre esses um estigmatizou Renan com a palavra "lixo". Nessa sala também estudavam duas meninas negras, uma delas a irmã de Rosa. Para além da cor da pele, a referência a crianças negras está expressa na classificação racial contida nos prontuários da escola.

Rosa está cursando o estágio II da educação infantil, ali denominada pré-escola. A personagem em questão foi diagnosticada com paralisia cerebral. Tem o menor porte físico de sua sala, usa o cabelo bem curto e crespo, e a paralisia cerebral não é perceptível visualmente. Superou dificuldades iniciais e no tempo da pesquisa já se comunicava com poucas dificuldades de dicção. Mora em um local ainda mais periférico e sua mãe trabalha como faxineira.

$\mathrm{Na}$ sala mostrou-se seguidamente irrequieta e o caderno de campo registra momentos em que bateu em colegas. Em uma dessas vezes a professora comentou que batia "por inveja e ciúmes", pois era a única que, até aquele momento, não possuía mochila.

Pode parecer insignificante a referência à mochila, mas, ao contrário, tratava-se de uma mercadoria fundamental na distinção que localmente se fazia em relação à estratificação social, marcando as famílias que tinham "alguma estrutura" (professora de Rosa) e podiam comprar um item nem sempre barato. 
Outra questão permeava as opiniões sobre a menina com deficiência sem mochila. Sua mãe era considera "típica evangélica" (professora) e isso era posicionado no mesmo lugar simbólico da dificuldade orçamentária de uma faxineira. Ou seja, supostamente, o argumento da falta de recurso era potencializado com a rejeição a símbolos mundanos, como, por exemplo, as mochilas ornadas com gravuras Disney.

Registrar momentos em que Rosa batia nas meninas tornou-se recorrente, mas quando ameaçou, por exemplo, um menino, deparou-se com a ameaça do revide, "levaria um soco" (menino ameaçado). Em cenários externos à sala, era possível registrar interações afetivas com as mesmas meninas que agredira, o que não impedia que muitas mães encaminhassem reclamações contra a inércia da escola em relação à "menina que bate" (vice-diretor).

Para a professora, ela agia de modo a transparecer a vida difícil que tinha, pois os aspectos religiosos da mãe incidiam com proibições para que a criança participasse de atividades sociais promovidas na escola. Mesmo assim, Rosa era considerada exemplo de superação, já que se notava diferença expressiva entre o momento em que chegou e aquele em que pesquisávamos.

No que toca às reações de Rosa aos demais, especialmente aquelas que terminavam em agressões, há um paralelo a ser feito em relação ao que se observou no cotidiano do ambulatório. Repetia-se o padrão de censura baseado não na recusa à agressividade em si, mas à incompatibilidade entre o modo de reagir e o "que se espera de uma menina" (professora).

Algumas situações proporcionavam aproximações estratégicas para nós e possibilitavam, tal como sugere Corsaro (2000) em suas etnografias com crianças, presenciar por dentro a lógica das brincadeiras e registrar algumas "reproduções interpretativas". Em outras palavras, algumas situações possibilitavam participar de microcerimônias em que papéis sociais eram repassados com releituras das próprias personagens. Rosa conseguia compor situações de modo a passar-se por bebê em cenas com outras crianças que performavam a pré-ensaiada condição de mães.

Até aquele momento, Rosa não tinha aprendido a escrever o nome, o que repunha "efeitos da deficiência” nas falas docentes na sala dos professores. Mas nas atividades com massinhas e outros materiais atendia às propostas como as demais, embora, nesse sentido, a queixa da professora se voltasse para a facilidade com a qual ela se desinteressava de qualquer atividade.

Quando foi possível dialogar com as professoras sobre Rosa ser uma menina negra e visivelmente uma das mais pobres, a primeira menção foi rapidamente descartada: "aqui ninguém é negro, todos têm a mesma oportunidade e recebem o mesmo tratamento".

\section{A observação na perspectiva dos observados}

A vida familiar de Rosa era constantemente evocada como recurso considerado indispensável para entender suas dificuldades. A viuvez da mãe era mencionada como fator de sobrecarga com tarefas para a filha mais velha, que também estudava na escola. Mas igualmente justificava a percepção de um "ambiente pouco estimulante" (diretora).

As dificuldades para andar e a comunicação pouco verbal apresentadas por Rosa quando foi matriculada foram consideradas evidências de "limites vividos na casa" (diretora) e a desenvoltura manifesta com o passar do tempo, considerada evidência dos "benefícios da socialização" (estagiária).

A diretora da escola afirmou que no início Rosa não andava plenamente e não se comunicava oralmente porque era limitada dentro de casa, e que fora o convívio com os demais alunos o responsável por "aflorar essas habilidades".

Rosa demonstrava muito carinho com a professora, e esta retribuiu compartilhando seu número de WhatsApp com a família, do que resultou troca de mensagens sonoras, dado que é relevante considerando as dificuldades de fonação provocadas pela paralisia cerebral. 
A insistência da professora convenceu a mãe a comprar a mochila para a criança e isso, na opinião de várias protagonistas daquele cotidiano escolar, deveria surtir algum efeito pacificador, uma vez que as queixas relacionadas ao "costume de agredir" (professora) aumentavam.

E foi no âmbito da observação que fazíamos com Rosa que sua professora indagou o quanto percebíamos a presença de Renan na escola, em outra turma, sugerindo comparações entre "o que é possível e o que é impossível para a escola”. Renan era a evocação do impossível.

Percebíamos intensamente essa "personagem" (Goffman, 2011) que Renan incorporava, considerando o sentido de incorporação baseado naquilo que Thomas Csordas (2008, p. 13) enfatiza ao lembrar que mais importante do que pensar em um corpo individual, conformado biologicamente, cabe reconhecer o "corpo no mundo" com seus diferentes modos de ser e estar.

Sua mobilidade é singular, usando na maior parte do tempo as mãos para arrastar-se em decorrência da imobilidade das pernas. Anda com as mãos, pois detesta os "pés redondos de ferro" (Haraway, 2010) que a cadeira de rodas disponível oferece. Raramente se abre à experiência que a órtese proporciona.

Esse menino negro, com expressiva redução de mobilidade, é sempre descrito como "resultado" (professora da sala dos professores) da família que tem. Ou que "não tem", conforme a avaliação geral.

Identificado com uma precariedade material mais intensa que a dos demais, ou seja, muito mais pobre que a maioria, é descrito como "largado, solto na rua até muito tarde" (diretora). Seu pai, já falecido, é mencionado pelo consumo de drogas e sua mãe é mencionada com citações de frases agressivas que ela dirigiu ao filho na presença de professores(as), entre as quais a mais lembrada era a que compartilhava sua expectativa de que "morresse logo".

Duas professoras referiam-se a ele como "áspero” e, de modo geral, quem falava sobre Renan principiava advertindo que "faltava muito" e que essa combinação entre "rejeição materna e ausência constante" (supervisora) retirava da escola qualquer possibilidade de ação concreta.

Se os avanços de Rosa eram comentados com manifestações que celebravam seu controle sobre o próprio corpo, suas dificuldades reverberavam "déficits no feminino", já que permanecia batendo em outras meninas. A professora reiterava que seu comportamento tinha algo a ver com "a frieza da mãe", observando que em atividade recente abrangendo mães e crianças na escola, a mãe de Rosa sequer permitiu que a filha a tocasse em uma atividade cuja razão de ser era justamente a interação corporal entre pequenas(os) e adultas(os).

Rosa mobilizava táticas (Certeau, 2000), convertendo instruções que recebia em possibilidades de sair da sala com amiguinhas, de auxiliar a professora e de acompanhar outras na ida ao banheiro.

Renan "negociava" seu aquietamento deixando-se conduzir à situação em que permaneceria sozinho, lidando com um laptop que ficava disponível no palco do pátio central. Os enquadramentos que recebeu das molduras de gênero se mostraram em circunstâncias muito singulares.

Como usualmente Renan se apoia nos próprios braços para andar, adquiriu musculatura e ganhou notoriedade pela velocidade e força com as quais se deslocava. Desse modo de andar resultaram mãos ressecadas. Ele mora com a mãe, o padrasto e duas irmãs gêmeas. Sempre que possível "lembra a todos que é um menino" (coordenadora).

Uma das crises mais significativas vividas por Renan na escola contou com o protagonismo dos demais meninos de sua sala. Em uma das poucas vezes em que se deslocou com a cadeira de rodas os demais meninos o empurraram para dentro do banheiro feminino.

Os gestos, palavras e modos de caçoar indicavam a associação que faziam entre a fragilidade de Renan e os "lugares de menina" (crianças), entre os quais marcadamente o banheiro específico.

Rosa e Renan eram crianças que causavam perplexidade porque eram consideradas indisciplinadas "apesar da deficiência" (professora).

As ações e reações de Renan recebiam agravantes quando eram analisadas por adultos(as) na escola. O que fosse considerado indisciplina era "diagnosticado" (professora) sempre com indicações de "personalidade violenta". 
Um dos professores de Renan o indagou a respeito de tantas brigas e ele respondeu afirmando que isso se dava porque "falavam mal dele". E nos momentos em que os conflitos adquiriam maior proporção e a direção era chamada a intervir reapareciam muitos argumentos que associavam suas ações ao fato de "ser menino" (professor e vice-diretor).

Profissionalmente, a escola era um ambiente repleto de mulheres, e a interlocução de Renan com os dois homens presentes, seu professor e o vice-diretor, alimentava a percepção geral de que "alguns assuntos dele fazem parte das questões masculinas" (coordenadora).

Quando Renan usava esse "ser menino" como recurso para impor-se diante dos demais, eram estes que repunham "seu lugar" como "homem porque bate, mas não homem porque nem faz xixi em pé” (coordenadora, ao interpretar a motivação para empurrá-lo para dentro do banheiro feminino).

Parecia que estávamos em um cenário de comprovação daquilo que Hall (2000) denominou dimensão relacional das marcações de identidade. Em relação aos demais meninos sua deficiência era associada a déficits de virilidade, e "nem batendo" ele lograria ver-se ou ser visto como "homem completo" (professor).

A fragilidade em Renan não era suficiente para que suas agressões deixassem de ser revidadas, pois o revide compunha a linguagem que plasmava os modos masculinos de responder. Ainda que os entreveros aproximassem corporalidades com notáveis dissimetrias, despontavam justificativas entre pares: "Bati também! Ele é homem ou não é?".

\section{Quando não há diferença entre estar e não estar}

Renan faltava muito. Rosa quase nunca.

Quando Renan estava presente, a lousa era preenchida com letra de forma para que ele pudesse copiar, atenuando a dificuldade com o ler e o escrever, o que nem sempre tinha receptividade de sua parte. Seu professor incentivava os demais para que tivessem ações de companheirismo com ele, mas considerava que o ideal seria ter um auxiliar para ele "enquanto" ensinava.

Esse lugar paralelo significado na projeção do "enquanto" como lugar dos que estão dentro, mas permanecem fora, mais uma vez nos lembrou os "excluídos no interior" mencionados por Bourdieu (2005). Mas havia diferença entre as situações de Renan e Rosa.

Rosa é considerada uma menina cuja socialização escolar a "salvou" da rudeza familiar. Renan é considerado intangível porque a família desestruturada não faz sequer o mínimo, deixando "toda a carga para a escola" (coordenadora).

Quando uma estagiária recebeu a incumbência de também acompanhá-lo, suas lições foram parcialmente feitas e a interrupção se dava quando ele, com alguma suavidade, informava estar cansado. De modo geral, Renan era afetuoso com o professor e com as crianças pequenas.

Renan copiava, mas não estava alfabetizado. Professoras e professores consideravam que ele demonstrava crescente assimilação de todas as consoantes e algum domínio sobre o encontro com as vogais. Em seus registros constava que compreendia bem as sílabas.

Gostava dos experimentos com slime, que é uma massa de modelar caseira usada na escola. Chegava a mostrar o que conseguiu fazer com a massa e demonstrava confiança na estagiária, acreditando, inclusive, que ela não comentaria com os demais a tarefa que executava com ele, que era a de trocar suas fraldas.

E foi em meio a tantos fios que se entreteciam naquele cotidiano que registramos que Renan passou a viver com a avó, pois sua mãe, segundo seu professor, permanentemente ameaçada de perder sua guarda desistiu e o deixou.

Uma professora considerou que Renan se "vitimizava”, buscando compensação para tudo o que uma "família desestruturada não lhe dava". E, com arroubos de psicologização, indicava que sua vida somente mudaria "quando ele fosse capaz de aceitar-se". 
Nos diálogos docentes que colocavam Renan em evidência e produziam análises invariavelmente estruturadas no dualismo, causa e consequência convergiam nas representações do acesso a direitos, reconhecendo aí a necessidade de defendê-lo pedagogicamente: "as crianças com autismo e Down têm acompanhamento, por que Renan também não tem?” (vice-diretor).

Foi possível reconhecer, na abundância de registros que tínhamos, que quase todas as personagens adultas da escola estavam dispostas, quase ávidas, a contar as experiências que tiveram com Renan. Em cada canto alguém testemunhava que presenciou espetaculosas reações de Renan.

Quando Renan sumiu, pois o Conselho Tutelar o levou para um abrigo, por muito tempo ainda foi mencionado. Renan, o ausente, era mais comentado que Rosa. Tornou-se uma personagem que, nos termos de Goffman (2000), não mais equivalia à identidade real que tinha, mas sim à identidade virtual que foi construída com base nas expectativas e estigmas que o acompanhavam.

\section{Sobre os limites da escola}

O corpo docente e diretivo da escola expôs inúmeras vezes opiniões que permitiam registrar contradições que permeavam o chão da escola quando o tema era educação inclusiva. Rosa e Renan, inclusive, eram mencionados como exemplos dos limites da escola.

Invariavelmente quando alusões a esses limites despontavam nas falas docentes e nas análises das pessoas que respondiam pela gestão, as impossibilidades pedagógicas eram apresentadas com base em duas premissas. A primeira reservava à família o papel decisivo para que "a inclusão pudesse dar certo ou não" (diretora).

Quando se estabelecia o consenso de que a criança vinha de uma "família desestruturada" ou em colapso (como se afirmava no caso da mãe de Renan que desistiu do menino até perder sua guarda), a inclusão passava a ser representada (Moscovici, 2010) como compensadora afetiva e reorganizadora daquilo que nas trocas simbólicas do cotidiano era descrito como autorrespeito e autoestima.

Inúmeras manifestações se reportavam queixosamente à "escassez de laudos” (diretora), situação que "obrigava a escola a agir sem saber" (coordenação pedagógica). Mas era também uma situação que "obrigava a escola a tirar informações com a família" (professor).

Nessas condições, procurando informações com familiares, os conflitos entre escola e casa tornavam-se intensos. A diretora externou compadecimento e, ao mesmo tempo, indignação com tudo o que viu e ouviu da mãe de Renan. Manifestou sua preocupação com os direitos educacionais que a escola devia ao menino, mostrando-se inconformada com a "desistência pedagógica" que muitos expressavam em relação às crianças com deficiência.

$\mathrm{Na}$ verbalização emocionada dessa indignação abriu espaço para considerar que o menino "além de deficiente é negro", possibilitando concluir que, no seu entender, deficiência e raça se interseccionavam. O vice-diretor fez comentário com conteúdo semelhante e as falas de ambos destoavam das muitas manifestações docentes que expressaram o convencimento de que "dentro da escola não fazia diferença ser branco ou preto" (professora).

A segunda premissa relacionada aos limites da escola despontou nas falas docentes que expressavam a compreensão de que "se o intelecto está preservado" as reações da criança derivam de seu "sentimento de inferioridade" (professor), sendo necessário inibir em todas as pessoas, principalmente na criança, sentimentos de "vitimização" (professora). Por isso, consideravam inaceitáveis as recusas que crianças com deficiência na escola por vezes apresentavam em usar tecnologias assistivas e órteses como, por exemplo, andadores e cadeiras de roda. A segunda premissa é formalizada com um lema: "a escola só ajuda quem se ajuda” (professora).

Essas premissas, que se manifestaram nas muitas indicações dos limites da escola, possibilitaram a estabilização de um consenso a respeito da situação de Renan. A maioria expressava tristeza por tantas dificuldades acumuladas em sua atribulada história e concluía que "o abrigo era a melhor opção para o menino" (coordenadora pedagógica). 


\section{Considerações finais}

Gênero, raça e classe social são categorias que se imbricam. No âmbito da educação inclusiva mostram-se fundamentais para que a presença de crianças com deficiência ou cronicamente enfermas no universo escolar seja analisada de modo a evitar reducionismos ou visões capacitistas que relacionam de modo simplificado o desempenho escolar às chamadas "insuficiências corporais". Nenhuma das questões comentadas neste texto diz respeito somente à deficiência em si, razão pela qual é possível concluir que nenhuma estratégia de escolarização especializada, segregadora, daria conta da complexidade que essas imbricações expuseram e expõem.

Os exemplos destacados e os excertos das falas podem suscitar a impressão de que não há abertura para a educação inclusiva, no âmbito da escola pública. Mas há, e já demonstramos isso em publicações anteriores, resultantes de pesquisas também desenvolvidas no chão da escola (Freitas \& Jacob, 2019).

Porém, é inegável que a escolarização de pessoas com deficiência ou cronicamente enfermas enfrenta desafios consideráveis e, por isso, nossa ênfase neste artigo incidiu sobre modos de reagir à questão, com a intenção de compartilhar nossa percepção de que o cerne de nossas insuficiências inclusivas não está na deficiência em si.

A importância das relações sociais que permitem a abordagem interseccional das deficiências e do adoecimento crônico em relação a outros fatores encontrados na experiência concreta de cada um(a) pode ser reconhecida, dialeticamente, pela negação.

Ou seja, reiteradas vezes, quando personagens do órgão de saúde ou da escola recebiam questões que sugeriam gênero, raça e classe social como conteúdos das situações abordadas, as palavras eram reconhecidas, mas secundarizadas, como se fossem sempre externalidades ao corpo limitado.

Uma síntese disso pode ser recon hecida no pedido que recebemos para que "um drama provocado pela natureza não fosse confundido com outras coisas" (professora). O viés da negação, gênero, raça e classe social mostrava-se imprescindível para entender, nos modos de recusar, o que se constrói em cada microssituação. Se não reconhecêssemos as intersecções que se apresentavam, a chamada incapacidade permaneceria representada como fio condutor da existência de cada personagem aqui analisada.

Quanto mais desconsideradas as questões que permitem abordagem interseccional em cada situação registrada, mais o espectro do capacitismo continua permeando convicções, diagnósticos e prognósticos.

Podemos, no momento em que fechamos este artigo, citar textualmente a manifestação de uma professora que tentou organizar nosso modo de compreender, tentou indicar o que faltava em nossa análise:

... não tem um que sabe menos ou o que tem mais dinheiro, não existe essa possibilidade e todos eles recebem ajuda na escola pública, se é uma escola particular pode ter diferenças, mas na escola pública essa diferença não aparece, porque todos eles recebem material, todos eles recebem a merenda igual, todos eles recebem uniforme, então aqui todo mundo é igual.

Essa fala é emblemática. Por um lado, contém um esforço para destacar um tratamento igualitário, o que muitas(os) reforçaram com outras palavras, em outras circunstâncias, diante do mesmo objeto, que é a presença da criança com deficiência ou cronicamente enferma. Por outro lado, concretamente essa manifestação se deu para reforçar de maneira enfática a recusa da professora em associar questões de gênero, raça e classe social às perguntas que fazíamos. Cotidianamente, há abertura educacional para a questão, mas há também grande resistência em deslocar o foco para aspectos que não estejam fixados apenas nas impossibilidades corporais.

Foi possível confirmar a hipótese de Goffman (2000) que indicou que, em dadas circunstâncias, algumas pessoas passam a ter uma identidade virtual, derivada daquilo que dela se fala, daquilo que dela se pensa, fundamentalmente construída com as expectativas a respeito de tudo que a pessoa (não) conseguirá. 
No ambulatório a teia de convivência que tecia a trama que acompanhamos suscitou uma demarcação que sintetizava, na fala de uma mulher, a intersecção entre deficiência, gênero, raça e classe social: "aqui todo mundo é preto".

Essa fala, ainda que vocalizada entre pares, movia-se politicamente de baixo para cima e compartilhava uma percepção de sofrimento social intraduzível sem considerar a resistência a um contexto que sempre lembra "o lugar de cada um" (enfermeira).

Com poucas exceções, as personagens da escola reelaboraram essa fala proclamando um lugar em que "todos são brancos”. As exceções fizeram e fazem muita diferença, mas essa fala contém um complexo vetor político, pois expressa a "maioria" que, a seu modo, se pronuncia de cima para baixo, marcando as assimetrias e desigualdades sociais como "desnecessárias" para compreender o contexto e, principalmente, personagens tão complexas como as que acompanhamos. Isso demonstra que a pesquisa no âmbito da educação especial, em perspectiva inclusiva, tem muito a ganhar assumindo como sua a densidade das perspectivas interseccionais.

\section{Referências}

Barton, L. (2017). Superar las barreras de la discapacidad. Cortez.

Berckmoes, L., \& Reis, R. (2017). Intergenerational transmission of violence and resilience in conflict-affected Burundi. Cambridge University Press.

Bluebond-Langner, M. (2000). In the shadows of illness. Princeton University Press.

Bourdieu, P. (2005). A miséria do mundo. Vozes.

Brah, A. (2006). Diferença, diversidade, diferenciação. Cadernos Pagu, 26, 329-376.

Brah, A. (2019). Ain't I a woman? Revisiting intersectionality. Journal of International Women's Studies, 5(3), $75-86$

Butler, J. (2015). Problemas de gênero: Feminismo e subversão da identidade. Civilização Brasileira.

Certeau, M. (2000). A invenção do cotidiano. Vozes.

Constituição da República Federativa do Brasil de 1988. (1988). http://www.planalto.gov.br/CCIVIL_03/ Constituicao/Constitui\%C\#\%A\&ao.htm

Corsaro, W. (2000). Sociology of childhood. Indiana University Press.

Corsaro, W. (2005). Transitions in early childhood. In R. Jessor \& A. Colby (Eds.), Ethnography and human development. Chicago University Press.

Crenshaw, K. (2002). Documento para o encontro de especialistas em aspectos da discriminação racial relativos ao gênero. Revista Estudos Feministas, 10(1), 171-188.

Csordas, T. (2008). Corpo, significado, cura. Editora da UFGRS.

Davis, A. (2010). Mulher, raça e classe. Plataforma Gueto.

Decreto n. 10.502 de 30 de setembro de 2020. (2020). Homologa nova Política Nacional de Educação Especial.

Diniz, D. (2010). O que é deficiência. Brasiliense.

Freitas, M. C. (2013). O aluno incluido na educação básica: Avaliação epermanência. Cortez.

Freitas, M. C., \& Jacob, R. N. (2019). Inclusão educacional de crianças com deficiência: Notas do chão da escola. Educação e Pesquisa, 45, e186303.

Garland-Thomson, R. (2002). Integrating disability: Transforming feminist theory. NWSA Journal, 14(3), $1-32$.

Geertz, C. (2000). A interpretação das culturas. Guanabara Koogan.

Goffman, E. (2000). Estigma: Notas sobre a manipulação da identidade deteriorada. LTC.

Goffman, E. (2011). A representação do eu na vida cotidiana. Vozes.

Goffman, E. (2012). Rituais de interação: Ensaios sobre o comportamento face a face. Vozes.

Goffman, E. (2013). The Goffman reader. Library of Congress Press.

Goffman, E. (2014). Comportamento em lugares públicos. Vozes.

Goffman, E. (2016). Os quadros da experiência social. Vozes. 
Gomes, R. B., \& Lopes, P. H. (2017). Estudos feministas da deficiência: Novas perspectivas e intersecções. In Anais, 11 Seminário Internacional Fazendo Gênero. Universidade Federal de Santa Catarina.

Hall, K. (2005). New conversations in feminist disability studies: Feminism, philosophy, and borders. Hypatia, $30(1), 1-12$.

Hall, S. (2000). Cultura e representação. Editora PUC-Rio.

Haraway, D. (2004). Gênero para um dicionário marxista: A política sexual de uma palavra. Cadernos Pagu, 22, 201-246.

Haraway, D. (2010). Antropologia do ciborgue. Autêntica.

Hirata, H. (2014). Gênero, classe, raça. Tempo Social, 26, 61-73.

Lei n. 13.146 de 6 julho de 2015. (2015, 6 julho). Institui a Lei Brasileira de Inclusão da Pessoa com Deficiência (Estatuto da Pessoa com Deficiência).

Lein. 9.394 de 20 de dezembro de 1996. (1996, 20 dezembro). Estabelece as Diretrizes e Bases da Educação Nacional. Martinez, A. M., \& Rey, F. G. (2017). Psicologia, educação e aprendizagem escolar. Cortez.

McRuer, R., \& Johnson, M. L. (2014). Proliferating cripistemologies: A virtual roundtable. Journal of Literary \& Cultural Disability Studies, 8(2), 149-169. https://www.muse.jhu.edu/article/548848

Mello, A. G. (2016). Deficiência, incapacidade e vulnerabilidade: do capacitismo ou a preeminência capacitista e biomédica do Comitê de Ética em Pesquisa da UFSC. Ciência e Saúde Coletiva, 21(10), 3265-3276.

Ministério da Educação. (2008). Politica Nacional de Educação Especial na Perspectiva da Educação Inclusiva, PNEEPEI.

Moscovici, S. (2010). Representações. Vozes.

Mozzi, A., \& Nuernber, A. H. (2017). Concepção sobre deficiência em processo de adoção de crianças com deficiência. Anais, 11 Seminário Internacional Fazendo Gênero. Universidade Federal de Santa Catarina.

Rockwell, E. (2014). La experiência etnográfica. Paidós.

Santillan, L. (2017). Quiénes educan a los chicos. Biblos.

Scott, J. W. (1995, julho/dezembro). Gênero: Uma categoria útil de análise histórica. Educação e Realidade, 2(20), 71-99.

Shakespeare, T. (1999). The sexual politics of disabled masculinity. Sexuality and Disability, 17(1), 53-64.

Shakespeare, T. (2010). The social model of disability. In L. Davis (Ed.), The disability studies reader (pp. 197-2014). Routledge.

Tremain, S. L. (2017). Foucault and the feminist philosophy of disability. University of Michigan Press.

Weber, F. (2010). Trabalho fora do trabalho: Uma etnografia das percepçôes. Garamond.

\section{Nota sobre autoria}

Ambos os autores contribuíram igualmente na concepção e redação do artigo.

\section{Disponibilidade de dados}

Os autores não disponibilizam os dados desta pesquisa, pois novos estudos ainda estão sendo desenvolvidos. Sendo assim, após o término, os dados poderão ser disponibilizados mediante consulta aos autores.

\section{Como citar este artigo}

Freitas, M. C. de, \& Santos, L. X. dos. (2021). Interseccionalidades e a educação especial na perspectiva da educação inclusiva. Cadernos de Pesquisa, 51, Artigo e07896. https://doi.org/10.1590/198053147896

Recebido em: 23 OUTUBRO 2020 | Aprovado para publicação em: 17 MARÇO 2021 